\title{
Panorâmica dos partos assistidos pelos(as) enfermeiros(as) obstétricos(as) de um Hospital Regional do sertão de Pernambuco
}

\author{
Overview of births attended by obstetric nurses at a Regional Hospital in the hinterland of \\ Pernambuco
}

\section{Resumen de los partos atendidos por enfermeras obstétricas en un Hospital Regional en el interior de Pernambuco}

Laíze Samara dos Santos ${ }^{1}$, Amuzza Aylla Pereira dos Santos ${ }^{2 *}$, Tâmara Silva de Lucena ${ }^{2}$, Roseane Leite Lopes ${ }^{3}$, Deborah Moura Novaes Acioli², Larissa de Morais Teixeira ${ }^{2}$, Julio Cesar Silva Oliveira², Rosa Patrícia Gomes Tenório Omena Rodrigues², José Augustinho Mendes Santos².

\section{RESUMO}

Objetivo: Identificar as práticas realizadas pelo(a) enfermeiro(a) obstétrico(a) na sala de parto visualizando a adoção das boas práticas obstétricas. Métodos: Estudo de abordagem quantitativa, descritiva e exploratória, dados coletados por meio formulário estruturado para entrevista com a puérpera e para análise dos prontuários, com a amostra de 146 puérperas e respectivos prontuários. Resultados: No quesito boas práticas obstétricas, a maioria recebeu água no trabalho de parto, foi estimulada a deambular e teve acompanhante, porém ainda de forma restrita. O banho morno e a massagem foram os métodos mais ofertados; a posição ginecológica ainda é a mais adotada pela mulher para parir, e ainda percebe-se ocorrer violências obstétricas, como manobra de kristeller, agressões verbais e episiotomia. Quanto a análise dos prontuários, a maioria não tinha partograma, nem tão pouco a descrição completa da assistência ofertada. Conclusão: A assistência dos enfermeiros obstétricos se aproxima das boas práticas, mas ainda precisa melhorar. Faz-se necessário extinguir as violências obstétricas, melhorar a adesão ao partograma e os registros em prontuário. Espera-se estimular discussões sobre esta temática e que o hospital estudado adote medidas de fortalecer a educação permanente com os profissionais que atuam na obstetrícia.

Palavras-chave: Enfermeiras obstétricas, Parto humanizado, Parto.

\begin{abstract}
Objective: To identify the practices performed by the obstetric nurse in the delivery room, visualizing the adoption of good obstetric practices. Methods: Study with a quantitative, descriptive and exploratory approach, data collected through a structured form for interview with the puerperal woman and for analysis of the medical records, with a sample of 146 mothers and their medical records. Results: Regarding good obstetric practices, most received water during labor, were encouraged to walk and had a companion, but still in a restricted way. The warm bath and massage were the methods most offered; the gynecological position is still the most adopted by women to give birth, and obstetric violence, such as the kristeller maneuver, verbal aggressions and episiotomy, is still perceived. As for the analysis of the medical records, most did not have a partogram, nor the complete description of the assistance offered. Conclusion: The assistance of obstetric nurses is close to good practices, but it still needs to improve. It is necessary to extinguish obstetric violence, improve adherence to the partogram and medical records. It is hoped to stimulate discussions on this theme and that the studied hospital will adopt measures to strengthen permanent education with professionals working in obstetrics.
\end{abstract}

Keywords: Nurse midwives, Humanizing delivery, Parturition.

1 Escola de Governo de Saúde de Pernambuco, Recife - PE.

2 Universidade Federal de Alagoas (UFAL), Maceió - AL. *E-mail: amuzza.santos@gmail.com

${ }^{3}$ Hospital Regional Inácio de Sá, Salgueiro - PE. 


\section{RESUMEN}

Objetivo: Identificar las prácticas realizadas por la enfermera obstétrica en la sala de partos, visualizando la adopción de buenas prácticas obstétricas. Métodos: Estudio con un enfoque cuantitativo, descriptivo y exploratorio, datos recopilados utilizando una forma estructurada para entrevistar a la mujer puerperal y para analizar los registros médicos, con la muestra de $d+$ y 146 madres y sus respectivos registros médicos. Resultados: En términos de buenas prácticas obstétricas, la mayoría recibió agua durante el parto, se les animó a caminar y tenían un compañero, pero aún de manera restringida. El baño caliente y el masaje fueron los métodos más ofrecidos; la posición ginecológica sigue siendo la más adoptada por las mujeres para dar a luz, y todavía se puede ver la violencia obstétrica, como la maniobra de kristeller, las agresiones verbales y la episiotomía. En cuanto al análisis de los registros médicos, la mayoría no tenía un partograma, ni la descripción completa de la asistencia ofrecida. Conclusión: La asistencia de las enfermeras obstétricas está cerca de las buenas prácticas, pero aún necesita mejorar. Es necesario extinguir la violencia obstétrica, mejorar la adherencia al partograma y a los registros médicos. Se espera estimular las discusiones sobre este tema y que el hospital estudiado adopte medidas para fortalecer la educación permanente con profesionales que trabajan en obstetricia.

Palabras clave: Enfermeras obstétricas, Parto humanizado, Parto.

\section{INTRODUÇÃO}

Até o final do século XIX, o parto foi considerado um evento natural, fisiológico, em que outras mulheres auxiliavam a gestante dar à luz. A parteira era o que havia de maior referência em conhecimento do partejar. Contudo, em meados do século XX, os homens da medicina começaram a intervir nesse processo, fazendo com que o modelo de assistência ao parto, que antes era domiciliar, passasse a ser institucionalizado, hospitalar. Assim, a atenção ao parto e nascimento tradicionais foram marcadas por uma ruptura da autonomia da mulher sobre sua própria história, instaurando-se a medicalização do parto, que passou a ser um evento médico seguido de diversas intervenções que tiraram da mulher autonomia na condução do parto (RIOS NKMA, et al., 2018).

No Brasil essa prática passou a ser rotineira por volta de 1960, e com o passar dos anos e a busca pela melhoria da assistência, o Ministério da Saúde (MS), através de suas normas e regulamentos, estabeleceu um conjunto de ações através de portarias ministeriais, que visa estimular a melhoria da assistência obstétrica, proporcionando a mulher um momento de acolhimento, no qual ela possa conduzir seu parto de forma a protagonizar todo o processo único vivenciados no trabalho de parto e nascimento (MEDEIROS RMK, et al., 2016).

Dessa forma, a humanização da assistência ao parto adota cuidados fundamentados na medicina baseada em evidências, bem como no protagonismo da mulher, sendo a integralidade e a individualidade aspectos fundamentais desta perspectiva de assistência. Cabendo as instituições de saúde a adoção de uma postura ética e solidária diante do acolhimento a mulheres em trabalho de parto e/ou parto (SILVA DF, et al., 2019)

Nesse contexto a Rede Cegonha, instituída pelo Ministério da Saúde no âmbito do Sistema Único de Saúde (SUS), propôs a criação de uma rede de cuidados que visa a assegurar à mulher o direito à atenção humanizada durante todo processo reprodutivo e a criança o direito ao nascimento seguro e ao crescimento e ao desenvolvimento saudáveis.

Essa estratégia ministerial, ainda coloca como um dos requisitos para o funcionamento do centro de parto normal (CPN), a garantia de que a condução da assistência ao parto de risco habitual, pós-parto fisiológico e cuidados com recém-nascido (RN) sadio, da admissão a alta, fossem realizados por obstetriz ou por Enfermeiro(a) Obstétrico(a) (BRASIL G, et al., 2018). Assim, torna-se essencial, que esses profissionais cuidem de forma igualitária, atentando para as necessidades físicas e psíquicas de cada mulher, considerando-as como ser único, que se encontra em um momento significativo de sua vida e enfrentando uma mistura de sentimentos e sensações em busca de cuidado e conforto. 
É neste contexto, que a busca pela compreensão dos aspectos relacionados à vivência do trabalho de parto e parto, torna-se importante para a otimização do cuidado, favorecendo a interação efetiva com a parturiente, proporcionando uma comunicação que pode acarretar em autoestima, apoio, conforto e confiança à mulher, resultando em segurança e satisfação (BRASIL, 2016).

Ao buscar identificar às práticas de cuidado prestados pelos enfermeiros obstétricos no processo parturitivo, percebe-se que os métodos não farmacológicos para alívio da dor, colaboram para progressão fisiológica do parto, e estão abarcados no cenário de cuidado humanizado.

Esses métodos são enquadrados pela Organização Mundial da Saúde (OMS) nas boas práticas obstétricas, comprovadamente benéficas as quais devem ser estimuladas no trabalho de parto e parto (PINHEIRO GQ, et al., 2019).

A importância da assistência humanizada durante o trabalho de parto está sendo uma temática atualmente em foco de discussões, no entanto, é evidente que ao passar dos anos houve um aumento significativo da medicalização e institucionalização do parto, além disto, é possível observar uma despersonalização da relação profissional/paciente, e isso acaba resultando em práticas distantes do que é recomendado, que não condizem com o atendimento que a mulher necessita e tem o direito de receber no momento do parto (SILVA DF, et al., 2019).

Diante da crescente atuação do enfermeiro obstétrico, o presente estudo tem como objetivo identificar as práticas realizadas pelo(a) enfermeiro(a) obstétrico(a) na sala de parto visualizando a adoção das boas práticas obstétricas.

\section{MÉTODOS}

Trata-se de um estudo de abordagem quantitativa, descritiva e exploratória. Os dados foram obtidos por meio de entrevista com as puérperas, através de um questionário estruturado e posterior análise dos prontuários por meio de um segundo questionário, realizando na análise dos dados uma comparação entre as informações declaradas e registradas.

Foram incluídas no estudo 270 puérperas, maiores de 18 anos, que tiveram parto normal assistidos por enfermeiros(as) obstétricos(as), na sala de parto dentro do bloco cirúrgico de um hospital regional do sertão central de Pernambuco, e que aceitaram participar por meio da assinatura do Termo de Consentimento Livre Esclarecido (TCLE), sendo excluídas desse grupo: 37 que se negaram a responder o instrumento ou não se dispuseram a assinar o Termo de Consentimento Livre Esclarecido (TCLE), 06 que apresentavam déficit cognitivo e 81 devido aos partos que foram assistidos por médicos, totalizando 146 puérperas e prontuários.

A população foi composta por uma média de partos normais do ano de 2018, com aproximadamente 870 partos/ano e 72,5 partos/mês. Assim a amostra foi construída baseada no cálculo amostral que se constituiu de 270 puérperas e seus prontuários, com um nível de confiança de 95\% e 5\% de percentual máximo pela calculadora amostral.

As variáveis analisadas foram: idade, escolaridade e estado civil, para os dados sociodemográficos. E para a avaliação da assistência foram analisados: oferta de líquidos, incentivo à livre deambulação, direito ao acompanhante, a posição que a mulher adotou ao parir, uso do partograma, utilização dos métodos nãofarmacológicos de alívio da dor (banho morno, massagem, música terapêutica e bola suíça), e práticas de manobra de Kristeller, episiotomia e agressão verbal, entendo como agressão verbal, a mulher relatar que escutou por parte da equipe, algo que não desejava referente ao contexto do gestar e parir. A análise dos dados foi realizada através de estatística descritiva, e exposta em gráficos e tabelas do Microsoft Excel 2013.

Vale salientar que o presente estudo atendeu as recomendações previstas na resolução 466/12 do Ministério da Saúde. Atendendo aos princípios e aspectos éticos o projeto de pesquisa foi submetido e aprovado pelo Comitê de Ética em Pesquisa da Universidade Federal de Alagoas-UFAL e aprovado sob o número CAAE 16673019.1.0000.5013. 


\section{RESULTADOS}

Observou-se que as puérperas estudadas estavam predominantemente na faixa etária entre 24 a 29 anos com $32 \%(n=47)$, quanto ao estado civil $44 \%(n=64)$ afirmaram ser solteiras, e quanto à escolaridade foi predominante o nível fundamental completo com 31,5\% $(n=46)$. Quanto aos dados obstétricos de paridade ocorreu a prevalência do grupo das secundigestas com $42,5 \%(n=62)$, seguido de $31 \%(n=45)$ primigestas e $27 \%(n=39)$ multíparas. Quanto à adoção das boas práticas pelos enfermeiros obstétricos, obtiveram-se resultados positivos, porém ainda abaixo do esperado. Sobre a oferta de líquidos, $70 \%(n=102)$ das mulheres relataram que receberam durante o trabalho de parto, porém em registro do prontuário, percebeu-se em apenas 18\% $(n=26)$ das assistências. Quanto ao incentivo à livre deambulação, $97 \%(n=141)$ das puérperas relataram, porém em registro de prontuário, observou-se em apenas $29 \%(n=42)$. Já quanto ao direito do acompanhante, apenas $66 \%(n=97)$ das parturientes, relataram a presença e em prontuário registrou-se em $27 \%(n=39)$ (Tabela 1).

Tabela 1 - Reconhecimento das boas práticas no parto, estimuladas/realizadas pelos enfermeiros obstétricos, de um hospital regional do sertão de Pernambuco, Brasil, 2019.

\begin{tabular}{ccccc}
\hline \multirow{2}{*}{ Práticas } & \multicolumn{2}{c}{ Puérperas } & \multicolumn{2}{c}{ Prontuário } \\
\cline { 2 - 5 } & $(\mathbf{n})$ & $\%$ & $26(\mathrm{Sim})$ & $\%$ \\
\hline Oferta de & $102(\mathrm{Sim})$ & $70 \%$ & $120(\mathrm{Não})$ & $82 \%$ \\
Líquidos & $44(\mathrm{Não})$ & $30 \%$ & $42(\mathrm{Sim})$ & $29 \%$ \\
\hline Incentivo à livre & $141(\mathrm{Sim})$ & $97 \%$ & $104(\mathrm{Não})$ & $71 \%$ \\
deambulação & $5(\mathrm{Não})$ & $3 \%$ & $39(\mathrm{Sim})$ & $27 \%$ \\
\hline Direito ao & $97(\mathrm{Sim})$ & $66 \%$ & 107 (Não) & $73 \%$ \\
Acompanhante & $49(\mathrm{Não})$ & $34 \%$ & & \\
\hline
\end{tabular}

Fonte: SANTOS LS, et al., 2020.

Outro contexto analisado, foi o uso dos métodos não-farmacológicos de alívio da dor, pelos enfermeiros obstétricos, notando-se que diante dos métodos disponíveis na instituição descritos na Tabela 2, o mais utilizado pelas parturientes foi o banho morno com $72 \%(n=105)$, seguido do uso da massagem $40 \%(n=58)$, música 34\% ( $n=49)$, bola suíça $16 \%(n=24)$. Quanto ao registro em prontuário, segue o mesmo contexto dos outros pontos analisados, com poucos registros sobre o uso dos métodos não-farmacológicos de alívio da dor (Tabela 2).

Tabela 2 - Uso dos métodos não-farmacológicos de alívio da dor, pelas parturientes, em um hospital regional do Estado de Pernambuco, Brasil, 2019.

\begin{tabular}{ccccc}
\hline \multirow{2}{*}{ Práticas } & \multicolumn{2}{c}{ Puérperas } & \multicolumn{2}{c}{ Prontuário } \\
\cline { 2 - 5 } & $(\mathbf{n})$ & $\%$ & $1 \mathbf{n})$ & $\%$ \\
\hline \multirow{2}{*}{ Bola suíça } & $24(\mathrm{Sim})$ & $16 \%$ & $10(\mathrm{Sim})$ & $7 \%$ \\
& $122(\mathrm{Não})$ & $84 \%$ & $136(\mathrm{Não})$ & $93 \%$ \\
\hline \multirow{2}{*}{ Música } & $49(\mathrm{Sim})$ & $34 \%$ & $22(\mathrm{Sim})$ & $15 \%$ \\
& $97(\mathrm{Não})$ & $66 \%$ & $121(\mathrm{Não})$ & $85 \%$ \\
\hline \multirow{2}{*}{ Massagem } & $58(\mathrm{Sim})$ & $40 \%$ & $24(\mathrm{Sim})$ & $16 \%$ \\
& $88(\mathrm{Não})$ & $60 \%$ & $122(\mathrm{Não})$ & $84 \%$ \\
\hline \multirow{2}{*}{ Banho Morno } & $105(\mathrm{Sim})$ & $72 \%$ & $35(\mathrm{Sim})$ & $24 \%$ \\
& $41(\mathrm{Não})$ & $28 \%$ & $111(\mathrm{Não})$ & $76 \%$ \\
\hline
\end{tabular}

Fonte: SANTOS LS, et al., 2020.

Quanto a adoção de posição para o parto, percebe-se que a posição ginecológica, ainda foi a mais adotada pelas parturientes, com $70 \%$ ( $n=102)$, seguida da posição de cócoras com $17 \%(n=25)$, a posição lateralizada com 9,5\% ( $n=14)$, seguida da posição de quatro apoios com 3,5\% (n=5), como descrito no Gráfico 1.

Quanto ao registro em prontuário, percebe-se que os enfermeiros obstétricos na descrição do parto, fazem referência ao posicionamento da mulher no parto, com maior frequência do que as demais assistências promovidas. 
Gráfico 1 - Posições adotadas pelas parturientes, em um hospital regional do sertão de Pernambuco, Brasil, 2019.

\section{Posições Adotadas no Parto}

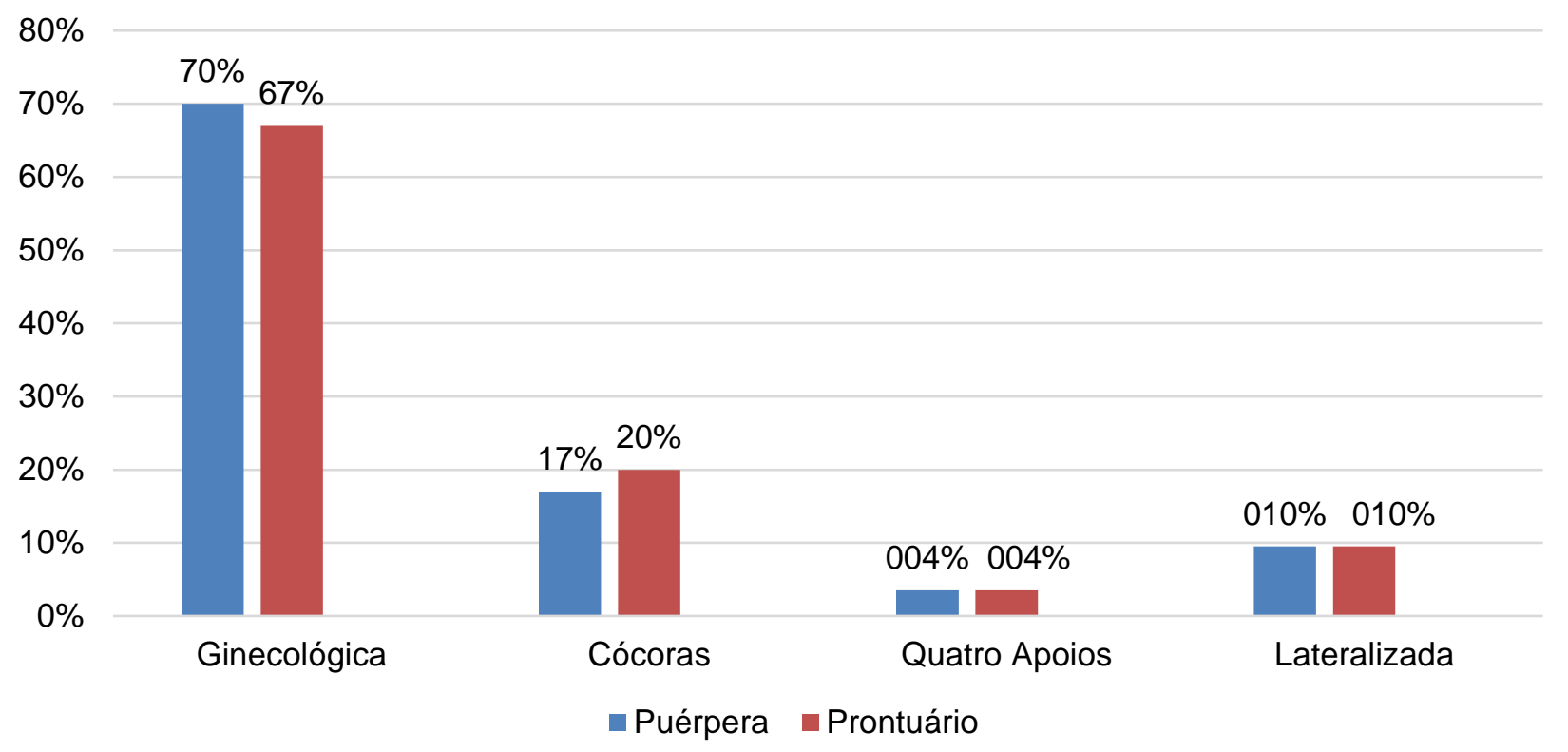

Fonte: SANTOS LS, et al., 2020.

No último bloco, o qual aborda as práticas descritas como violência obstétrica, percebe-se que a Manobra de Kristeller, apresenta uma alta prevalência neste estudo, chegando a $36 \%(n=52)$, assim como a episiotomia que ocorreu com 29,5\% ( $n=43)$ e a agressão verbal ocorreu com $19 \%(n=28)$ das parturientes.

Já em registro de prontuário, não foi registrada nenhuma das práticas de Manobra de Kristeller e agressão verbal. E a episiotomia teve apenas $6 \%$ de registro nos prontuários, e não se sabe em quais situações foram realizadas (Tabela 3).

Tabela 3 - Reconhecimento de práticas que remetem a violência obstétrica, no trabalho de parto e parto, em um hospital regional do sertão do Estado de Pernambuco, Brasil, 2019.

\begin{tabular}{ccccc}
\hline \multirow{2}{*}{ Práticas } & \multicolumn{2}{c}{ Puérperas } & \multicolumn{2}{c}{ Prontuário } \\
\cline { 2 - 5 } & (n) & $\%$ & (n) & $\%$ \\
\hline Manobra de & $52(\mathrm{Sim})$ & $36 \%$ & $0(\mathrm{Sim})$ & $0 \%$ \\
Kristeller & $94(\mathrm{Não})$ & $64 \%$ & $146(\mathrm{Não})$ & $100 \%$ \\
\hline \multirow{2}{*}{ Episiotomia } & $43(\mathrm{Sim})$ & $29,5 \%$ & $9(\mathrm{Sim})$ & $6 \%$ \\
& $103(\mathrm{Não})$ & $70,5 \%$ & $137(\mathrm{Não})$ & $94 \%$ \\
\hline \multirow{2}{*}{ Agressão Verbal } & $28(\mathrm{Sim})$ & $19 \%$ & 0 (Sim) & $0 \%$ \\
& $118(\mathrm{Não})$ & $81 \%$ & 146 (Não) & $100 \%$ \\
\hline
\end{tabular}

Fonte: SANTOS LS, et al., 2020.

Sabe-se que para acompanhar um trabalho de parto, o uso do partograma é recomendado, a fim de registrar parâmetros em gráfico, que gerem subsídios para a realização de alguma conduta necessária. Com base nisso, entende-se que ao passo que se utiliza este recurso, sugere-se menos intervenções sem indicação, desde que aberto em um momento oportuno. De acordo com isto, o Gráfico 2 mostra o percentil de prontuários com partogramas preenchidos, onde apenas $14 \%(n=21)$ deles, continha o recurso. 
Gráfico 2 - Uso do partograma pelos Enfermeiros Obstétricos em um hospital regional do sertão de Pernambuco, Brasil, 2019.

\section{Partograma}

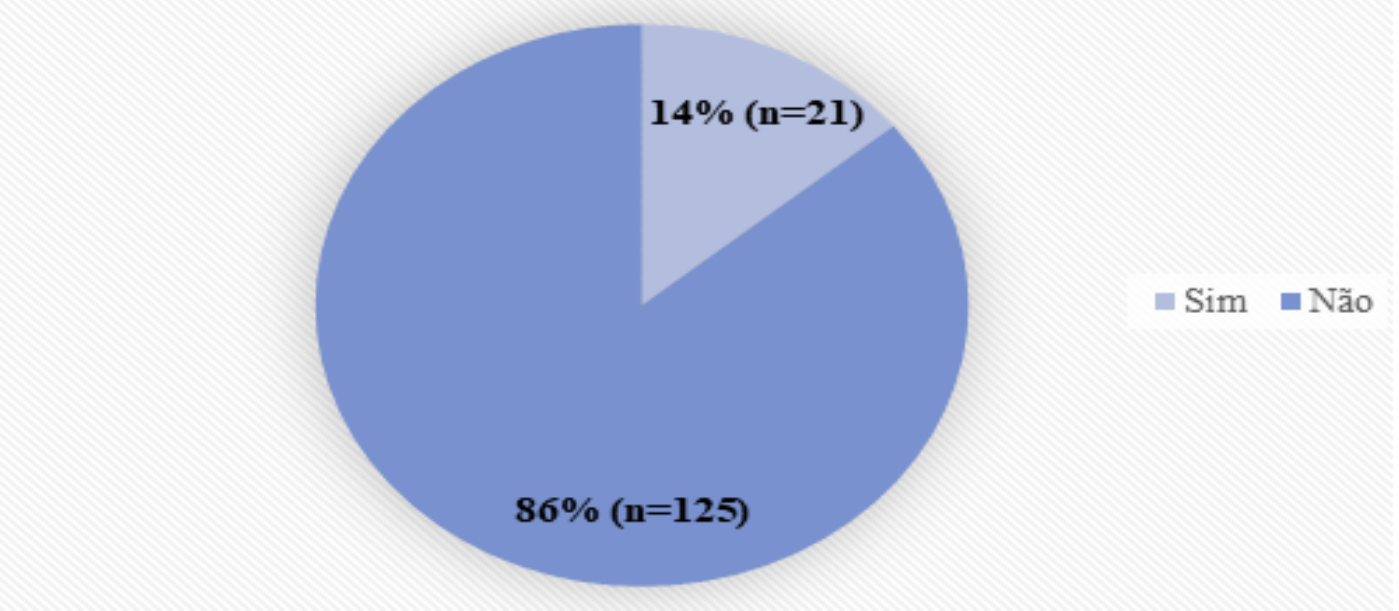

Fonte: SANTOS LS, et al., 2020.

\section{DISCUSSÃO}

As características sociodemográficas encontradas na amostra investigada tiveram predominância de mulheres com idades 24 a 29 anos com 32\% $(n=47)$, quanto ao estado civil $44 \%(n=64)$ afirmaram ser solteiras e quanto à escolaridade sobressaiu-se o nível fundamental completo com $31,5 \%(n=46)$. Tais dados discordaram quanto ao estado civil e escolaridade quando comparados com outros estudos que demonstraram um maior percentual de mulheres casadas ou que vivem em união estável e que possuem o ensino fundamental incompleto.

Assim como com a paridade, que em outros estudos mostraram que a maioria das mulheres entrevistadas são primigestas, e no presente estudo se sobressaiu às secundigestas (SILVA DF, et al., 2018; BEZERRA A, et al., 2018). Sendo assim os achados podem corroborar com um dos critérios de inclusão da pesquisa, que selecionou o grupo de mulheres maiores de 18 anos, excluindo o grupo de notória representatividade, quando se mostra em outros estudos a prevalência da gestação na adolescência.

Sobre o predomínio da enfermagem na assistência obstétrica, e adesão às boas práticas, reforça a sua importante contribuição no que se refere à prática assistencial. Nesse sentido destacam-se em alguns estudos, condutas que se apoiam na humanização da assistência, como o direito a acompanhante, liberdade de posição e movimento, utilização de métodos não farmacológicos de alívio da dor, baixa prevalência de episiotomia e de toques vaginais sucessivos, além de se evitar hospitalizações precoces. Tendo em vista que a enfermagem obstétrica visa boas práticas para mudanças paradigmáticas com um parto humanizado e seguro que devolva o protagonismo da mulher no parto (BRASIL G, et al., 2018; BEZERRA A, et al., 2018).

Não corroborando com os achados, diante a oferta de líquidos no trabalho de parto, estudos mostram que em muitos países desenvolvidos, o receio de aspiração de conteúdo gástrico durante a anestesia geral (Síndrome de Mendelson) continua a justificar a regra de abstenção total de alimentos ou líquidos durante o trabalho de parto. Essa preocupação excessiva dos profissionais com a restrição alimentar deve-se à possibilidade de a parturiente regurgitar durante um procedimento anestésico, porém, evidências apontam que o risco de aspiração está diretamente associado ao uso de anestesia geral no parto, que é muito baixo (AZEVEDO LS, et al., 2020).

No caso das gestantes, o fato de manter-se em jejum não é garantia de manter o estômago vazio, pois, independentemente do tempo da última refeição, sempre haverá um resíduo de volume gástrico de, no mínimo, $100 \mathrm{ml}$. O risco de aspiração do conteúdo gástrico leva a um medo real e sério, entretanto, a restrição da ingesta de líquidos e alimentos durante o trabalho de parto não é uma garantia de diminuição de conteúdo estomacal (AZEVEDO LS, et al., 2020; WHO, 2018). 
Quanto ao incentivo à livre deambulação, mostra-se que ele vem sendo bem aplicado, quando reconhecido por $97 \%(n=141)$ das puérperas, como uma das orientações dadas pelos enfermeiros obstétricos. Sabe-se que a deambulação durante o trabalho de parto apoia a fisiologia do nascimento e melhora a experiência do parto para a mulher pois, favorece a irrigação do útero, as contrações são mais eficazes, diminui o tempo do trabalho de parto, ajuda o feto a adaptar-se à bacia materna e alivia a dor (SILVA DF, et al., 2018; LUZ SC, 2017).

Correspondendo aos achados do presente estudo, o Royal Colege of Midwives aconselha as parteiras a serem pró-ativas, devendo demonstrar, encorajar e apoiar as parturientes a adotar a deambulação, e a movimentação durante o trabalho de parto (ROYAL-COLLEGE-OF-MIDWIVES, 2010).

Sobre o posicionamento da parturiente no ato de parir, a Organização Mundial da Saúde tem diretivas que apontam para as medidas que devem orientar o parto normal, das quais se destaca a importância da liberdade de posição, de movimento e o encorajamento na adoção de posições não supinas, durante o trabalho de parto e parto. Apesar da maioria dos profissionais de saúde especializados, nesta área, serem detentores de conhecimentos, prevalece os argumentos de como a posição dorsal é a mais vantajosa para o bem-estar materno-fetal.

A justificação é fundamentada, a maioria das vezes, por essa posição, pois possibilita uma monitorização contínua e mais adequada durante o trabalho de parto, além de permitir mais facilmente realizar a avaliação da progressão do mesmo, é fundamental para a realização de analgesia epidural contínua, durante o trabalho de parto, esquecendo-se na maior parte das vezes de questionar a necessidade e a vantagem de todas estas intervenções (OMS, 1996).

Sobre a aplicabilidade dos métodos não-farmacológicos de alívio da dor, estes podem auxiliar a parturiente no alívio da dor durante o trabalho de parto, além de promover uma sensação de bem-estar para a mulher, proporcionando-Ihe satisfação e diminuindo o estresse, tornando assim, o processo do parto menos doloroso e tenso, quando realizados por profissionais capacitados. Fazendo aqui a referência aos enfermeiros(as) obstétricos(as), percebe-se que estes tem otimizado a assistência ao parto normal, respeitando a mulher em um momento ímpar de sua vida, promovendo a ocorrência da humanização do cenário do parto (FORTES AFA e FIGUEIREDO GCN, 2015).

Quanto ao direito à presença do acompanhante, o presente estudo ainda apresenta uma prevalência muito baixa da acessibilidade do acompanhante a sala de parto, indo contra o que é previsto pela Lei Federal no 11.108, de 07 de abril de 2005, mais conhecida como a Lei do Acompanhante, a qual determina que o acompanhante seja indicado pela gestante, podendo ser o pai do bebê, o parceiro atual, a mãe, um(a) amigo(a), ou outra pessoa de sua escolha (BRASIL, 2005).

Quando 34\% ( $n=49)$ das puérperas que afirmaram que não puderam ser acompanhadas no momento do parto, evidenciando o descumprimento da lei. Pois diante a vivência da assistência no serviço, os motivos que parecem levar a esse dado, precede mais da imposição do profissional que assiste o parto, do que por outros motivos. A presença do acompanhante proporciona bem-estar físico e emocional à mulher e favorece uma boa evolução do período gravídico-puerperal. Além disso, pode diminuir as complicações no pré-parto, no parto e no puerpério, a utilização de analgesia, de ocitocina e o tempo de hospitalização do binômio mãe-filho (CAMARGO CM, et al., 2019).

Sobre a realização da episiotomia, observou-se na Tabela 3, a realização da mesma, em $29,5 \%(n=43)$ das mulheres entrevistadas, enquanto dessas, apenas $6 \%(n=9)$ estavam registradas em prontuário. Percebese uma alta prevalência de uma prática já colocada diante as evidências científicas como desnecessária na assistência ao parto.

Há a necessidade de estimular modelos de atendimentos singulares e humanizados por parte dos profissionais, pois a episiotomia é um dos procedimentos que mais tem levantado discussões atualmente, por ser um procedimento que não deve ser realizado rotineiramente (NUNES RD, et al., 2019). Além de provocar maior perda sanguínea e rompimento de estruturas importantes que podem gerar consequências físicas e psíquicas à mulher (SANTOS RCS e SANTOS RG, 2016). 
Analisando os dados referente à episiotomia esses números superam, e muito, a porcentagem recomendada pela Organização Mundial de Saúde (OMS) que sugere uma taxa ideal de episiotomia nos diversos serviços em torno de 10\%, realidade em muitos países europeus. Contudo, não existe um consenso na literatura sobre quais seriam essas situações, somente que seu uso deveria se restringir a situações clínicas específicas, de acordo com a determinação do serviço (POMPEU KC, et al., 2017).

Diante o registro da realização da episiotomia, percebe-se a falha na falta de registro em prontuário, perdendo o respaldo profissional, quando não mencionado os motivos que levaram a prática de episiotomia, afastando-se da linha do cuidado humanizado. Corroborando assim, com os autores quando trazem que os registros de enfermagem no prontuário do paciente, são essenciais para a continuidade do cuidado. Todavia os registros de enfermagem muitas vezes não se constituem em motivo de preocupação para a equipe, que os fazem de maneira rápida e não clara, ou não relatam integralmente a assistência realizada (CANDIDO ASG, et al., 2018)

A falta de conhecimento das mulheres sobre os seus direitos no parto e a falha dos profissionais em esclarecer os procedimentos antes de serem realizados, agridem física e emocionalmente os direitos da mulher, deixando-a exposta a intervenções inadequadas que a colocam em riscos, como a manobra de Kristeller, que aumenta o risco de inversão uterina e hemorragia. O momento do parto é muito esperado pelas mulheres, porém, violências obstétricas traumatizam e fazem a mulher carregar tais lembranças para o resto da vida. Portanto a prática do Kristeller deve ser abolida, pois além de ser agressivo para a mãe, pode trazer consequências que levem ao óbito (LIMA GAF e LOPES MCA, 2019). É preciso existir uma divulgação maior em relação à proibição da prática de manobra de Kristeller, com base nas políticas públicas de prevenção, que conscientizem a população quanto ao parto humanizado, de forma que as mulheres saibam reconhecer uma violência obstétrica, exigindo a efetivação dos seus direitos (FERREIRA JB, et al., 2018)

Outra prática considerada violência obstétrica é a agressão verbal à mulher, que também foi citada na Tabela 3. A agressão verbal acontece quando qualquer ato verbal gera na mulher, o sentimento de inferioridade, vulnerabilidade, abandono, insegurança e instabilidade emocional. Nas maternidades, essas agressões acontecem em forma de piadas, ameaças, humilhações, desrespeito pessoal ou cultural, informações oferecidas em linguagem pouco acessível, ofensas e omissão de informações. Para mudar esta realidade de violência, deve haver maior preparo dos profissionais com discussão deste tema na formação de graduação, especialização e em atividades de educação em saúde, nos serviços (BITTENCOURT AC e OLIVEIRA SL, 2019).

Diante todos os pontos analisados, o preenchimento do partograma seria uma ferramenta com capacidade de reduzir as intervenções desnecessárias, porém apresenta-se de forma ineficaz no presente estudo. No Gráfico 2, é possível analisar que apenas $14 \%(n=21)$ apresentaram este instrumento, mesmo sabendo que quando preenchido da forma correta, o partograma garante segurança durante a assistência obstétrica.

Estudos apontam que seu uso ainda é pouco e quando utilizado, muitas vezes é possível identificar o preenchimento incorreto, que acabar por comprometer a qualidade do acompanhamento do trabalho de parto (ROCHA KS, et al., 2017). E ainda além de oportunizar um acompanhamento de qualidade, o partograma apresenta-se como um instrumento de respaldo legal para o profissional que assiste ao parto. Sobre a documentação do paciente, o prontuário e os demais documentos inerentes ao processo de cuidados de enfermagem (livros de ocorrência, relatórios, etc.) constituem a finalização do processo de cuidar do paciente, traz maior visibilidade a profissão, permite o planejamento da assistência, refletem a produtividade da equipe, permitem que sejam feitas estatísticas de atendimento, servem de fonte de consulta para inspeção da auditoria de enfermagem, são provas cabais da jornada de trabalho e ainda, poderão servir para a defesa ou incriminação de profissionais de saúde (PINHEIRO AB, et al., 2019).

\section{CONCLUSÃO}

Percebeu-se que a assistência dos enfermeiros obstétricos está passando por um processo lento de aproximação com as boas práticas, existindo ainda muitas limitações na assistência, principalmente quando se refere à acessibilidade do acompanhante de livre escolha, ao preenchimento do partograma e ainda a 
adoção das práticas da manobra de Kristeller, da episiotomia e de agressão do tipo verbal, que descaracterizam a assistência baseada nos preceitos da humanização do parto. Diante de tantos debates sobre a autonomia do enfermeiro(a) obstétrico(a) na sala de parto, o estudo permitiu dar notoriedade a aplicabilidade das práticas realizadas por estes profissionais, demonstrando a partir dos resultados, que ainda precisa ocorrer uma maior adesão as boas práticas obstétricas, mostrando a necessidade de se trabalhar a educação permanente no serviço como ferramenta importante para a atualização e mudança da prática profissional. Os achados não se restringem ao cenário de estudo da pesquisa, sendo uma realidade, que se observa em diversos cenários de assistência ao parto, entretanto espera-se estimular discussões sobre esta temática e que os serviços de assistência ao parto, adotem medidas que promovam o fortalecimento da educação permanente com os enfermeiros obstétricos, assim como percebam que a humanização do parto é um processo continuo de troca entre parturiente, equipe e serviço.

\section{REFERÊNCIAS}

1. AZEVEDO LS, et al. Métodos não Farmacológicos para o Alívio da Dor Durante o Trabalho de Parto. Revista Vivências, Erechim, 2020; 16(30): 115-125.

2. BEZERRA A, et al. Percepção da mulher acerca da assistência ao parto pela enfermeira obstetra. Rev. Enferm. Foco 2018; 9(4): 28-33.

3. BITTENCOURT AC, OLIVEIRA SL. Significado e percepção da violência obstétrica para os profissionais que atuam na assistência ao trabalho de parto e parto. In: Seminário de Iniciação Científica, FAPEMING, 2019, 1(1): 1-5.

4. BRASIL G, et al. Parto no Brasil: intervenção médica ou protagonismo da mulher? Scire Salutis, 2018, 8(2): 9-23.

5. BRASIL. Lei $n^{0} 11.108$, de 7 de abril de 2005. Altera a Lei no 8.080, de 19 de setembro de 1990, para garantir às parturientes o direito à presença de acompanhante durante o trabalho de parto, parto e pós-parto imediato, no âmbito do Sistema Único de Saúde - SUS. Brasília, Diário Oficial [da] União, 8 abr. 2005, Seção 1.

6. CAMARGO CM, et al. A eficácia dos métodos não farmacológicos aplicados pelo enfermeiro obstetra no alívio da dor do trabalho de parto. Rev Cient Esc Est Saúde Pública Goiás "Cândido Santiago". 2019; 5(2):64-75

7. CANDIDO ASG, et al. Informações de Enfermagem registradas nos prontuários frente às exigências do Conselho Federal de Enfermagem]. Rev Paul Enferm. 2018; 29(1-2-3): 31-8.

8. FERREIRA JB, et al. Assistência de enfermagem ao parto: manobra de Kristeller. Enfermagem Obstétrica, 2018; 5(94): 1-6.

9. FORTES AFA, FIGUEIREDO GCN. Percepções e sentimentos das puérperas acerca da presença do acompanhante de sua escolha no pré, trans e pós-parto imediato. Enfermagem Brasil, 2015, 14(1): 21-28.

10. LIMA GAF, LOPES MCA. Violência Obstétrica: Riscos do Uso da Manobra de Kristeller Durante o Parto. UNICEPLAC, 2019, 1(1): 4-18.

11. LUZ SC, SANTOS MAF. Contributos da deambulação para a progressão do Trabalho de Parto. ESEL, Lisboa. 2017, 1(1): 20-36

12. MEDEIROS RMK, et al. Humanized Care: insertion of obstetric nurses in a teaching hospital. Rev Bras Enferm. 2016; 69(6): 1029-36.

13. BRASIL. Diretriz Nacional de Assistência ao Parto Normal. Brasília (DF): Ministério da Saúde, 2016.

14. NUNES RD, et al. Avaliação dos fatores determinantes à realização da episiotomia no parto vaginal. Enferm. Foco 2019; 10 (1): 70-75.

15. ORGANIZAÇÃO MUNDIAL DA SAÚDE (OMS). Boas práticas de atenção ao parto e ao nascimento. Geneva: OMS, 1996.

16. PINHEIRO AB, et al. Registro da assistência de enfermagem: visão dos gestores de enfermagem de duas unidades hospitalares do sertão central cearense. EEDIC, 2019; 1(1): 1-6.

17. PINHEIRO GQ, et al. O Processo de parto: A importância do enfermeiro no parto humanizado. Rev Inic Cient Ext. 2019; 2(4): 190-5.

18. POMPEU KC, et al. Prática da episiotomia no parto: Desafios para a enfermagem. Revista de Enfermagem do CentroOeste Mineiro. 2017; 7:e1142.

19. RIOS NKMA, et al. O processo de parir assistido pela enfermeira obstétrica sob a luz da Teoria Humanística. Cadernos Esp. 2018; 12(1): 80-90.

20. ROCHA KS, et al. Aplicabilidade e preenchimento correto do partograma como instrumento de segurança na assistência obstétrica. INTERNATIONAL NURSING CONGRESS. May 9-12, 2017, 1-4.

21. ROYAL-COLLEGE-OF-MIDWIVES. The Royal College of Midwives Survey of positions used in labour and Birth Final report. London, 2010.

22. SANTOS RCS, SANTOS RG. Fatores relacionados com a prática da episiotomia no Brasil: revisão de literatura. Estação Científica (UNIFAP), 2016, 6(2): 43-52.

23. SILVA DF, et al. Conhecimento das gestantes sobre as posições do parto. Rev. Refaci, Brasília, 2018; 1(1): 1-9.

24. SILVA TMA, et al. Significados e práticas da equipe de enfermagem acerca do parto humanizado: uma revisão de literatura. Rev. Braz. J. Surg. Clin. Res., 2019; 26(1): 90-94.

25. WHO. WORLD HEALTH ORGANIZATION. WHO recommendations: intrapartum care for a positive childbirth experience, 2018. 